\title{
Comparative Pharmacokinetics and Bioavailability of Three Ephedrines in Rat after Oral Administration of Unprocessed and Honey-Fried Ephedra Extract by Response Surface Experimental Design
}

\author{
Yezhe Cheng, ${ }^{1}$ Yu Zhang, ${ }^{2}$ Hang Xing, ${ }^{2}$ Kun Qian, ${ }^{1}$ Longshan Zhao, ${ }^{2}$ and Xiaohui Chen ${ }^{2}$ \\ ${ }^{1}$ School of Traditional Chinese Materia Medica, Shenyang Pharmaceutical University, Shenyang 110016, China \\ ${ }^{2}$ School of Pharmacy, Shenyang Pharmaceutical University, Shenyang 110016, China \\ Correspondence should be addressed to Longshan Zhao; longshanzhao@163.com and Xiaohui Chen; cxh_syphu@hotmail.com
}

Received 2 March 2017; Accepted 12 April 2017; Published 19 June 2017

Academic Editor: Dolores García Giménez

Copyright (C) 2017 Yezhe Cheng et al. This is an open access article distributed under the Creative Commons Attribution License, which permits unrestricted use, distribution, and reproduction in any medium, provided the original work is properly cited.

Ephedra have been used as a common traditional Chinese medicine for thousands of years. However, the perspiration effect of the unprocessed ephedra was too strong. Clinical trials have shown that processing methods play a critical role in moderating the perspiration property of ephedra according to the needs. A LC-MS/MS method was developed and validated to compare the pharmacokinetic properties of the three ephedrines after oral administration of unprocessed and honey-fried ephedra extract. The contents of honey, frying temperature, and frying time were set at $20 \%, 116^{\circ} \mathrm{C}$, and 7 min by the Box-Behnken response surface method, respectively. In the pharmacokinetics study, the biosamples were pretreated and extracted by protein precipitation method with acetonitrile and separated on an Agilent TC- $\mathrm{C}_{18}$ column $(250 \mathrm{~mm} \times 4.6 \mathrm{~mm}, 5 \mu \mathrm{m})$ using a mobile phase consisting of $0.1 \%$ formic acid methanol and $5 \mathrm{mM}$ ammonium acetate aqueous solution $(5: 95, \mathrm{v} / \mathrm{v})$. All calibration curves were linear $(r>0.9932)$ with lower limits of quantitation (LLOQs) $<12 \mathrm{ng} / \mathrm{mL}$. The mean recoveries of the three analytes were higher than $75 \%$. The pharmacokinetics study indicated that the reduced absorption of ephedrine hydrochloride (EH) and pseudoephedrine hydrochloride $(\mathrm{PEH})$ in honey-fried ephedra group might be the main reason for the moderation of the diaphoretic property.

\section{Introduction}

Ephedra (Mahuang in Chinese), the dried stems of Ephedra sinica Stapf, Ephedra intermedia Schrenk et C. A. Mey. and Ephedra equisetina Bge. from Ephedraceae [1], has been widely used for thousands of years for treatment of allergies, asthma, pneumonia, chills, edema, colds, and fever [2-9]. However, the perspiration effect of the unprocessed ephedra was too strong and would cause the qi consuming, body fluid damaging, and imbalance of qi-blood and yin-yang, especially for the elderly, children, or weak patients. Clinical trials have shown that processing methods play a critical role in moderating the perspiration property of ephedra according to the needs [10]. The traditional processing methods for ephedra are various [11]; honey-fried is one of the most significant processing methods. Honey was natured, sweet, and nontoxic, benefitting for nourishing yin and moistening lungs. After processing, the diaphoresis and antitussive and antiasthmatic effect of honey-fried ephedra was gentler [12, 13]. Therefore, preparing the best effect honey-fried ephedra was beneficial to the rational application of honey-fried ephedra and unprocessed ephedra. Most of the processing methods recorded in the literatures were simple subjective description and lacked experimental data support. Hence, it was difficult to prepare the best effect honey-fried ephedra.

Response surface methodology (RSM) was a prominent mathematical and statistical technique. In recent years, RSM was used to optimize, develop, and improve different products or processes and to evaluate the simultaneous effects of several factors. It was initially described and developed by Box and Wilson (1951) [14-21]. Box-Behnken design (BBD), one of the most popular response surface designs, 
was advantageous due to its widespread use and versatility [22-24]. This design provided efficient solutions and less experimental runs and thus was more economical approach and was used to assess the mathematical relationship between the multiple independent variables so as to determine and optimize the appropriate processing technology of ephedra [22, 25-27].

Based on the traditional processing methods, this paper mainly optimized and determined the processing technology of honey-fried ephedra and compared the variations of effective components. The effects of different contents of honey, frying temperature, and frying time on relative contents of ephedrine hydrochloride (EH), pseudoephedrine hydrochloride $(\mathrm{PEH})$, and methylephedrine hydrochloride $(\mathrm{MEH})$ in honey-fried ephedra have been investigated by using BBD. Better understanding of the processing technology of honeyfried ephedra was beneficial to clinical use of unprocessed ephedra and honey-fried ephedra.

As far as we know, with oral administration as the main route of administration of traditional Chinese Medicine [28], the absorption of active ingredients is the first link to exert therapeutic effect, which should be given enough attention. Up to now, the research on ephedra processing has often focused on the processing technology and the comparison of pharmacological action. In addition, there were few reports on the pharmacokinetics study of bioactive compounds after oral administration of unprocessed ephedra extract and honey-fried extract. Phytochemical and pharmacological studies revealed that $\mathrm{EH}, \mathrm{PEH}$ exerted significant diaphoretic, antitussive, and antiasthmatic effects, and $\mathrm{MEH}$ exerted primary antitussive and antiasthmatic effects. Moreover, these three ephedrines were the main biologically active ingredients in ephedra [8,27-34].

According to the previous research and experimental conditions, the purpose of this paper was to optimize and determine the processing technology of honey-fried ephedra and to investigate the pharmacokinetic profiles of $\mathrm{EH}, \mathrm{PEH}$, and $\mathrm{MEH}$ after oral administration of unprocessed ephedra extract and honey-fried extract. In this paper, we present a validated LC-MS/MS method for simultaneous determination of the three ingredients in rat plasma. Additionally, pharmacokinetic parameters of the three ingredients in unprocessed ephedra extract and honey-fried extract were described.

\section{Materials and Methods}

2.1. Materials and Reagents. Ephedra (Ephedrae Herba, Batch number 201611) was purchased from Nei Monggol Chifeng Rongxingtang Drug Co., Ltd. (Shenyang, China) and identified by Associate Professor YanNian Wang, a traditional Chinese medicine (TCM) identifying expert from Department of Traditional Chinese Medicine Processing, Shenyang Pharmaceutical University. The contents of $\mathrm{EH}, \mathrm{PEH}$, and $\mathrm{MEH}$ were quantitatively determined by HPLC and were 9.5, 8.4, and $1.1 \mathrm{mg} / \mathrm{g}$ in ephedra, respectively. EH (Batch number 171241201607; purity, 99.7\%), MEH (Batch number 171247-201601; purity, 99.9\%), PEH (Batch number 171237-201608; purity, $100 \%$ ), and internal standard (matrine; purity > 98.5\%) were purchased from the National Institute for the Control of Pharmaceutical and Biological Products (Beijing, China). Methanol and acetonitrile of HPLC grade were supplied by Fisher Scientific (Pittsburgh, PA, USA). Ether and isopropyl alcohol (analytical grade) was purchased from Kermel Chemical Reagent Co. Ltd. (Tianjin, China). Distilled water was obtained from Wahaha Co. Ltd. (Hangzhou, China).

2.2. Animals. Twelve Male Sprague-Dawley rats weighted 280-300 g were obtained from the Experimental Animal Center of Shenyang Pharmaceutical University. The rats were bred in an air conditioned animal center at a temperature of $25 \pm 2{ }^{\circ} \mathrm{C}$ and a relative humidity of $50 \pm 10 \%$, with a natural light-dark cycle for 7 days, and then fasted overnight with only access to water for $12 \mathrm{~h}$ before the experiment. Animal study was conducted with strict adherence to the Guideline of Animal Experimentation of Shenyang Pharmaceutical University, and the experimental protocols were approved by the Animal Ethics Committee of the institution.

2.3. Response Surface Experimental Design. The effects of different contents of honey, frying temperature, and frying time on relative contents of $\mathrm{EH}, \mathrm{PEH}$, and $\mathrm{MEH}$ in honeyfried ephedra were investigated by the single factor method, which was utilized by the Box-Behnken response surface method. On the basis of the single factor experimental results, three major influence factors were confirmed, and then a RSM was conducted to design experimental project. As shown in Table 1 . The three factors chosen for this study were designated as $\mathrm{A}, \mathrm{B}$, and $\mathrm{C}$ and prescribed into three levels, adjusted as +1 (maximum), 0 (central), and -1 (minimum).

2.3.1. HPLC-DAD Conditions. The system consists of an Agilent $\mathrm{TC}-\mathrm{C}_{18}$ column $(4.6 \mathrm{~mm} \times 250 \mathrm{~mm}, 5 \mu \mathrm{m})$ with mobile phase of acetonitrile- $0.1 \%$ phosphoric acid and $0.1 \%$ triethylamine water $(4: 96, \mathrm{v} / \mathrm{v})$ at a flow rate of $0.8 \mathrm{~mL} / \mathrm{min}$. The column temperature was set at $30^{\circ} \mathrm{C}$ and the detection wavelength was set at $210 \mathrm{~nm}$.

2.3.2. Standard Solution. The stock solutions of $\mathrm{EH}, \mathrm{PEH}$, and $\mathrm{MEH}(1.604 \mathrm{mg} / \mathrm{mL}, 1.510 \mathrm{mg} / \mathrm{mL}$, and $0.507 \mathrm{mg} / \mathrm{mL}$, resp.) were prepared in methanol. The chemical structures of EH (a), PEH (b), and MEH (c) are shown in Figure 1. A series of mixed working standards having $10-320 \mathrm{ng} / \mathrm{mL}$ for $\mathrm{EH}, 9-302 \mathrm{ng} / \mathrm{mL}$ for $\mathrm{PEH}$, and $1-30 \mathrm{ng} / \mathrm{mL}$ for $\mathrm{MEH}$ were obtained by diluting a mixture of the stock solutions with methanol. All the solutions were stored at $-20^{\circ} \mathrm{C}$.

2.3.3. Preparation of Samples with Different Processing Conditions. The right amount of samples was mixed well with diluted honey (the contents of honey were $10 \%, 20 \%$, and $30 \%)$ and was moistened for $12 \mathrm{~h}$. Then, the samples were fried with different temperature $\left(110^{\circ} \mathrm{C}, 120^{\circ} \mathrm{C}\right.$, and $\left.130^{\circ} \mathrm{C}\right)$ and were fried until losing their stickiness (frying time was $6 \mathrm{~min}, 8 \mathrm{~min}$, and $10 \mathrm{~min}$ ). Each of the foregoing samples was prepared variously for three until use. 
<smiles>CN[C@H](C)[C@H](O)c1ccccc1</smiles>

(a) Ephedrine<smiles>C[C@H](O)[C@H](C)c1ccccc1</smiles>

(c) Methylephedrine<smiles>CN[C@H](C)[C@H](O)c1ccccc1</smiles>

(b) Pseudoephedrine<smiles>O=C1CCCC2C3CCCN4CCCC(CN12)C34</smiles>

(d) Matrine

FIgURE 1: Chemical structures of EH (a), PEH (b), MEH (c), and IS matrine (d).

TABLE 1: Box-Behnken design and observed response.

\begin{tabular}{|c|c|c|c|c|c|c|}
\hline \multirow[b]{2}{*}{ Number } & \multirow{2}{*}{$\begin{array}{c}\text { A } \\
\text { Content of honey }(\%)\end{array}$} & \multirow{2}{*}{$\begin{array}{l}\text { B } \\
\text { Frying time (min) }\end{array}$} & \multirow{2}{*}{$\begin{array}{c}\mathrm{C} \\
\text { Frying temperature }\left({ }^{\circ} \mathrm{C}\right)\end{array}$} & \multicolumn{3}{|c|}{$Y$ content $(\mathrm{mg} / \mathrm{g})$} \\
\hline & & & & $\begin{array}{c}\mathrm{EH} \\
Y_{1} \\
\end{array}$ & $\begin{array}{c}\mathrm{PEH} \\
Y_{2} \\
\end{array}$ & $\begin{array}{c}\mathrm{MEH} \\
Y_{3} \\
\end{array}$ \\
\hline 1 & 10 & 10 & 120 & 6.291 & 5.551 & 0.673 \\
\hline 2 & 20 & 6 & 130 & 6.243 & 5.722 & 0.669 \\
\hline 3 & 20 & 8 & 120 & 8.419 & 7.279 & 0.866 \\
\hline 4 & 20 & 6 & 110 & 7.103 & 6.753 & 0.713 \\
\hline 5 & 20 & 10 & 130 & 3.182 & 3.398 & 0.284 \\
\hline 6 & 20 & 10 & 110 & 6.733 & 6.362 & 0.590 \\
\hline 7 & 30 & 8 & 130 & 3.958 & 3.732 & 0.424 \\
\hline 8 & 20 & 8 & 120 & 8.394 & 7.307 & 0.861 \\
\hline 9 & 20 & 8 & 120 & 8.403 & 7.315 & 0.872 \\
\hline 10 & 30 & 10 & 120 & 5.019 & 4.883 & 0.560 \\
\hline 11 & 20 & 8 & 120 & 8.376 & 7.286 & 0.870 \\
\hline 12 & 10 & 8 & 130 & 3.800 & 3.462 & 0.328 \\
\hline 13 & 10 & 8 & 110 & 7.310 & 5.985 & 0.787 \\
\hline 14 & 30 & 8 & 110 & 7.146 & 6.646 & 0.756 \\
\hline 15 & 30 & 6 & 120 & 6.516 & 6.113 & 0.590 \\
\hline 16 & 20 & 8 & 120 & 8.419 & 7.286 & 0.870 \\
\hline 17 & 10 & 6 & 120 & 7.237 & 6.937 & 0.713 \\
\hline
\end{tabular}

2.4. Instruments and LC-MS/MS Conditions. The liquid chromatographic analysis was performed using a Shimadzu (Japan, Kyoto) LC-MS/MS 2010EV system equipped with electrospray ionization (ESI) interface. The separation was achieved on an Agilent TC- $\mathrm{C}_{18}$ column $(250 \mathrm{~mm} \times 4.6 \mathrm{~mm}$, $5 \mu \mathrm{m}$ ) at $30^{\circ} \mathrm{C}$ using methanol (A)- $0.1 \%$ formic acid and $5 \mathrm{mM}$ ammonium acetate water (B) $(5: 95, \mathrm{v} / \mathrm{v})$ as initial proportion of the isocratic elution. The flow rate was set at $0.8 \mathrm{~mL} / \mathrm{min}$ and the injection volume was $20 \mu \mathrm{L}$. The IS were ionized by electrospray ionization source in positive ion mode under the following source conditions: nebulizing gas $1.5 \mathrm{~L} / \mathrm{min}$, desolvation line (DL) temperature $250^{\circ} \mathrm{C}$, heat block temperature $200^{\circ} \mathrm{C}$, detector voltage $1.75 \mathrm{kV}$, and other parameters were fixed as the tuning file. Analysis was carried out by SIM mode for $\mathrm{EH}[\mathrm{M}+\mathrm{H}]^{+} \mathrm{m} / z$ 166.20, $\mathrm{PEH}[\mathrm{M}+\mathrm{H}]^{+}$ $m / z$ 166.20, MEH $[\mathrm{M}+\mathrm{H}]^{+} \mathrm{m} / z$ 180.20, and IS $[\mathrm{M}+\mathrm{H}]^{+} \mathrm{m} / z$ 249.35. The chemical structures of EH (a), PEH (b), MEH (c), and the IS matrine (d) are shown in Figure 1 and the full-scan 


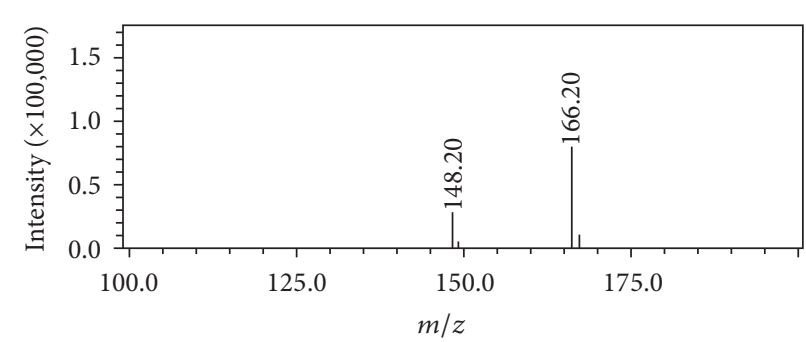

(a)

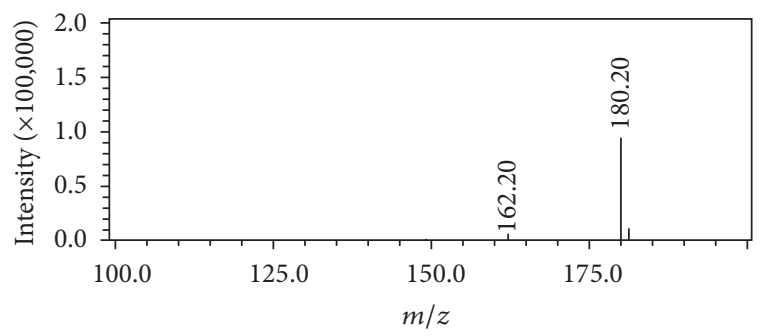

(c)

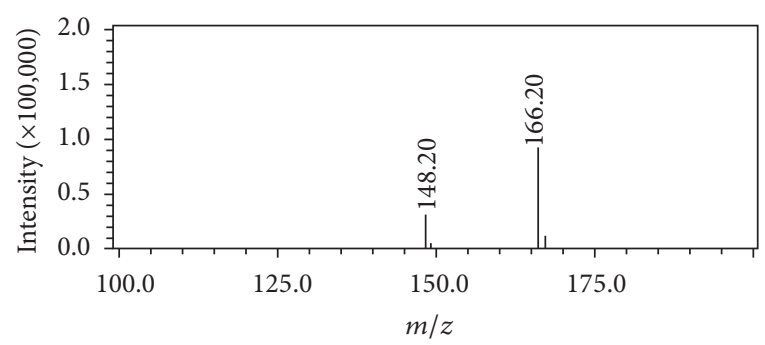

(b)

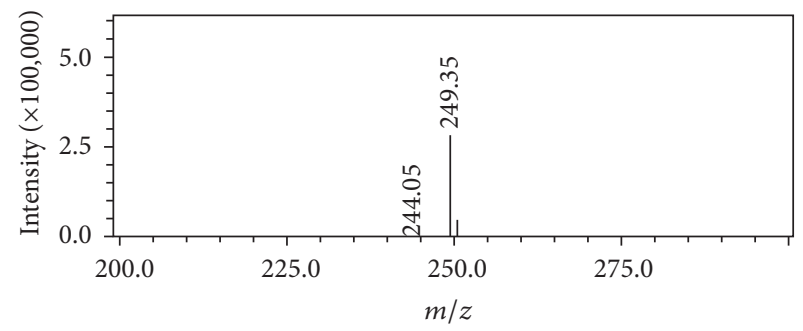

(d)

FIgure 2: The LC-MS/MS product ion mass spectra: the $[\mathrm{M}+\mathrm{H}]^{+} \mathrm{m} / z 166.20$ for $\mathrm{EH}(\mathrm{a})$, the $[\mathrm{M}+\mathrm{H}]^{+} m / z 166.20$ for $\mathrm{PEH}(\mathrm{b})$, the $[\mathrm{M}+\mathrm{H}]^{+}$ $\mathrm{m} / z 180.20$ for $\mathrm{MEH}$ (c), and the $[\mathrm{M}+\mathrm{H}]^{+} \mathrm{m} / z 249.35$ for IS (d).

mass spectra of four analytes after injection in mobile phase are shown in Figure 2.

2.5. Preparation of Ephedra Extract. The powder of unprocessed ephedra $(5 \mathrm{~g})$ was extracted twice by refluxing with water $(1: 10, \mathrm{w} / \mathrm{v}), 1 \mathrm{~h}$ for each time. Then the extraction solutions were combined, filtered, and evaporated to dryness. The solution contained the equivalent of approximately $3.0 \mathrm{~g}$ of unprocessed ephedra per $\mathrm{mL}$ and was stored at $-20^{\circ} \mathrm{C}$ until use. This preparation was the unprocessed ephedra extract. The same procedure was followed for the preparation of the honey-fried ephedra extracts: using the powder of honeyfried ephedra $(5 \mathrm{~g})$ to produce honey-fried ephedra extract.

2.6. Standard Solution and Quality-Control Samples. The stock solutions of $\mathrm{EH}, \mathrm{PEH}, \mathrm{MEH}$, and IS were prepared with methanol at concentrations of $1.604 \mathrm{mg} / \mathrm{mL}$, $1.510 \mathrm{mg} / \mathrm{mL}, 0.507 \mathrm{mg} / \mathrm{mL}$, and $9 \mu \mathrm{g} / \mathrm{mL}$, respectively. A series of mixed working standards having $40-16,000 \mathrm{ng} / \mathrm{mL}$ for $\mathrm{EH}, 60-15,000 \mathrm{ng} / \mathrm{mL}$ for $\mathrm{PEH}$ and $30-1,500 \mathrm{ng} / \mathrm{mL}$ for $\mathrm{MEH}$ were obtained by diluting a mixture of the stock solutions with methanol. In addition, the stock solution of the IS was diluted to a concentration of $900 \mathrm{ng} / \mathrm{mL}$ with methanol as working solution. All the solutions were stored at $-20^{\circ} \mathrm{C}$.

The calibration standards of $\mathrm{EH}(8,20,80,320,1280$, and $3200 \mathrm{ng} / \mathrm{mL}), \mathrm{PEH}(12,60,120,480,1200$, and $3000 \mathrm{ng} / \mathrm{mL})$, and $\operatorname{MEH}(6,15,30,75,150$, and $300 \mathrm{ng} / \mathrm{mL})$ were prepared by adding $20 \mu \mathrm{L}$ of the mixed working standard solution to blank plasma. Three levels of quality-control (QC) samples at concentrations of 20, 256, and $2560 \mathrm{ng} / \mathrm{mL}$ for $\mathrm{EH}, 30,240$, and $2400 \mathrm{ng} / \mathrm{mL}$ for $\mathrm{PEH}$ and 15, 60, and $240 \mathrm{ng} / \mathrm{mL}$ for $\mathrm{MEH}$ in plasma were prepared separately in the same method. All of the solutions were stored at $-20^{\circ} \mathrm{C}$ for further study.
2.7. Sample Preparation. Prior to analysis, all frozen subject samples including rat plasma samples, calibration standards, and QC samples were thawed and allowed to equilibrate at room temperature. The $100 \mu \mathrm{L}$ plasma sample spiked with $20 \mu \mathrm{L}$ IS (matrine $900 \mathrm{ng} / \mathrm{mL}$ ) and $50 \mu \mathrm{L}$ sodium carbonate solution $(0.1 \mathrm{~mol} / \mathrm{L})$ were vortex-mixed for $30 \mathrm{~s}$. The resulting sample was subjected to protein precipitation with $200 \mu \mathrm{L}$ acetonitrile and then vortex-mixed for $5 \mathrm{~min}$. After centrifugation at $4500 \mathrm{rpm}$ for $10 \mathrm{~min}$, the supernatant was transferred into another new tube and evaporated to dryness at ambient temperature with a gentle steam of nitrogen. Finally, the residue was dissolved with $100 \mu \mathrm{L}$ initial mobile phase and $20 \mu \mathrm{L}$ was injected for LC-MS/MS analysis.

\subsection{Method Validation}

2.8.1. Specificity, Linearity, and Lower Limit of Quantification. Specificity was evaluated by comparing chromatograms from blank plasma with those obtained from the corresponding plasma spiked with EH (18.6 min), PEH (20.3 min), MEH (22.7 $\mathrm{min})$, and IS (12.3 min) and plasma samples after oral administration of unprocessed ephedra extract. Linearity was assessed by analyzing the calibration curves $(8-3200 \mathrm{ng} / \mathrm{mL}$ for $\mathrm{EH}, 12-3000 \mathrm{ng} / \mathrm{mL}$ for $\mathrm{PEH}$, and $6-300 \mathrm{ng} / \mathrm{mL}$ for $\mathrm{MEH}$ ) in plasma by plotting the peak area ratio (analyte/IS) versus the normalized standard concentration of the analytes. The lower limit of quantification (LLOQ) was defined as the lowest concentration of the calibration curve with an accuracy and precision within the recommended $\pm 20 \%$ from their nominal values.

2.8.2. Precision and Accuracy. The accuracy and precision were evaluated by analyzing QC samples in six replications at low, medium, and high concentrations per day and over a 
period of three consecutive days. The precision was expressed as the relative standard deviation percentage (RSD\%), while the accuracy was expressed as relative error percentage (RE\%).

2.8.3. Extraction Recovery and Matrix Effect. The extraction recovery and matrix effect at three QC concentrations were evaluated in sets of six replicates. The recoveries of three analytes and the IS were determined by comparing the peak areas obtained from the extracted samples with the analytes spiked before and after extraction.

The matrix effect was measured by comparing the peak areas of analytes added to postextracted blank with analytes dissolved in matrix component-free reconstitution solvent.

2.8.4. Stability. The stability of the analytes in spiked rat plasma samples was investigated at three QC levels under different storage conditions: three cycles of freezing at $-20^{\circ} \mathrm{C}$ and thawing, at the storage temperature $\left(-20^{\circ} \mathrm{C}\right)$ for 14 days, at room temperature $\left(25^{\circ} \mathrm{C}\right)$ for $8 \mathrm{~h}$, and stability and in autosampler $\left(4^{\circ} \mathrm{C}\right)$ for $12 \mathrm{~h}$.

\subsection{Method Application}

2.9.1. Drug Administration and Sampling. Animals housed on cages were randomly divided into two groups, with six rats in each group. All the rats were fasted for $12 \mathrm{~h}$, with free access to water prior to the experiments. After giving $3 \mathrm{~g} / \mathrm{kg}$ of unprocessed ephedra extract and honey-fried ephedra extract (calculated by crude drug) to each group by oral gavage using a stomach tube, about $0.3 \mathrm{~mL}$ of the blood samples was obtained from the orbital plexus of the eyes at $0,0.08,0.17,0.33,0.5,1,2,4,6,8,12$, and $24 \mathrm{~h}$ which were placed in heparinized tubes and immediately centrifuged at $6000 \mathrm{rpm}$ for $5 \mathrm{~min}$. The separated plasma samples were finally stored at $-80^{\circ} \mathrm{C}$ until analysis.

2.9.2. Pharmacokinetic Analysis. All pharmacokinetic parameters were analyzed using the Drug and Statistics (DAS) 2.1 software package supplied by Chinese Pharmacological Society and expressed as means \pm standard deviation (SD). The comparison of pharmacokinetic data of $\mathrm{EH}, \mathrm{PEH}$, and $\mathrm{MEH}$ was determined by SPSS 19.0 (Statistical Package for the Social Science) via independent samples $t$-tests after their natural logarithmic transformation or the Mann-Whitney test $[35,36]$. A value of $P<0.05$ was considered statistically significant for all the tests. The data are presented as mean \pm SD.

\section{Results and Discussion}

3.1. Results of Response Surface Experiment. The response surface experiment was designed with 15 test points, of which 12 were the factorial points, and the 3 was the zero points. The zero points were the central points of the region, and it was necessary to repeat the experiment for 3 times to estimate the experimental error. Specific BBD and observed responses were shown in Table 1.
3.2. The Establishment of Regression Equation Model and Significance Test. Using the data in Table 1 and statistical software Design-Expert V. 8.0.6 to regress and fit, the contents of EH, $\mathrm{PEH}$, and $\mathrm{MEH}$ were taken as the responses $Y_{1}, Y_{2}$, and $Y_{3}$. Predicted responses $Y_{1}, Y_{2}$, and $Y_{3}$ could be expressed by the following second-order polynomial equations:

$$
\begin{aligned}
Y_{1}= & 8.40-0.25 A-0.73 B-1.39 C-0.14 A B \\
& +0.091 A C-0.67 B C-1.20 A^{2}-0.94 B^{2} \\
& -1.65 C^{2}, \quad R^{2}=0.9729, \\
Y_{2}= & 7.29-0.07 A-0.67 B-1.18 C+0.039 A B \\
& -0.098 A C-0.48 B C-1.01 A^{2}-0.41 B^{2} \\
& -1.33 C^{2}, \quad R^{2}=0.9671, \\
Y_{3}= & 0.87-0.021 A-0.072 B-0.14 C+2.500 E \\
& -003 A B+0.032 A C-0.066 B C-0.11 A^{2} \\
& -0.12 B^{2}-0.18 C^{2}, \quad R^{2}=0.8956 .
\end{aligned}
$$

The results indicated that the regression equations were significant; the model had a good fit to the experiment and represented the relationship between the responses and factors. The model could be used to analyse and predict the contents of $\mathrm{EH}, \mathrm{PEH}$, and $\mathrm{MEH}$ under different processing conditions.

3.3. The Analysis and Optimization of Response Surface. According to the regression equation model, the relationship between the responses and the experimental variables can be illustrated graphically to investigate the interactions of the variables and to determine the optimal level of each variable for the maximum response by plotting three-dimensional response surface plots. After investigating the shape of the response surface, the effects of different contents of honey, frying temperature, and frying time on relative contents of $\mathrm{EH}, \mathrm{PEH}$, and $\mathrm{MEH}$ were analyzed. As shown in Figure 3, the response surface plots directly reflected the influence of each factor and interaction on the response values.

3.4. Determination of Optimum Processing Conditions. According to the analysis of statistical software Design-Expert V. 8.0.6, the optimal processing conditions of $\mathrm{EH}, \mathrm{PEH}$, and $\mathrm{MEH}$ were, respectively, obtained.

The contents of honey, frying temperature, and frying time were set at $18.97 \%, 116.26^{\circ} \mathrm{C}$, and $7.50 \mathrm{~min}$ for $\mathrm{EH}$; the contents of honey, frying temperature, and frying time were set at $19.69 \%, 116.70^{\circ} \mathrm{C}$, and $6.76 \mathrm{~min}$ for $\mathrm{PEH}$; the contents of honey, frying temperature, and frying time were set at $18.50 \%$, $116.30^{\circ} \mathrm{C}$, and $7.60 \mathrm{~min}$ for $\mathrm{MEH}$.

Consequently, the optimum processing conditions were established. The contents of honey, frying temperature, and frying time were set at $20 \%, 116^{\circ} \mathrm{C}$, and $7 \mathrm{~min}$, respectively.

All of the honey-fried ephedra mentioned above was prepared with the optimum processing conditions. 

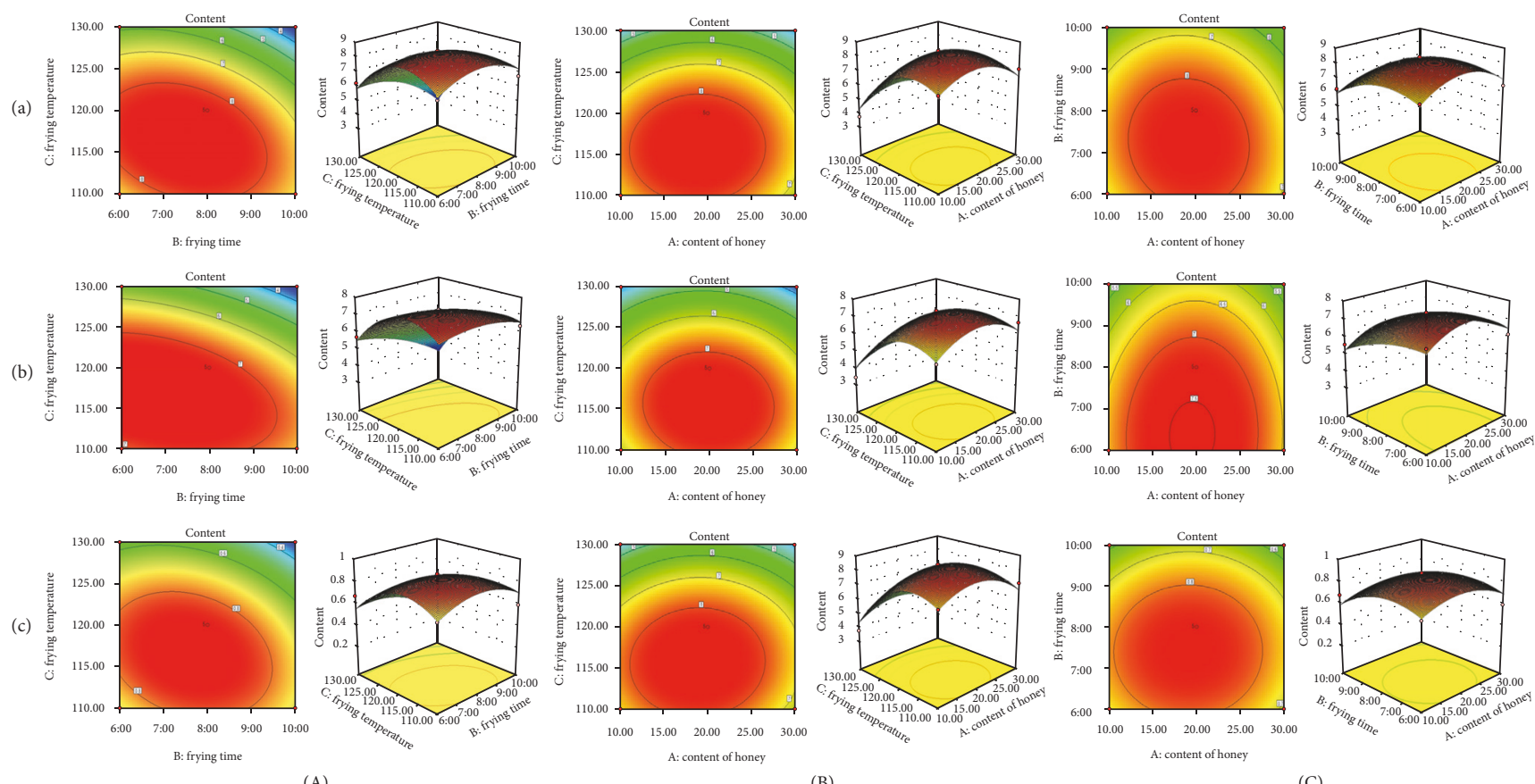

(A)
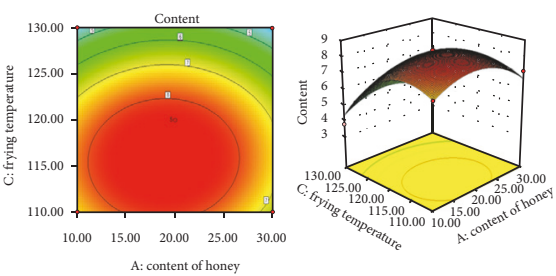

(B)
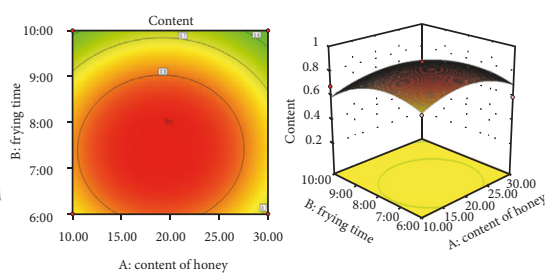

(C)

FIGURE 3: Response surface and contour plot showing interactive effect of different factors on the extraction content of EH (a), PEH (b), and MEH (c). (A) Frying time and frying temperature; (B) content of honey and frying temperature; (C) frying time and content of honey.

3.5. Response Surface Experiment Study. One of the strengths of RSM is that it can work well in many cases where there is incomplete knowledge about the study, such as the processing technology of honey-fried ephedra, which lacks theoretical direction and experimental data. The BBD, as a significant response surface design, provides vast quantities of information, avoidance of extreme conditions, and less experiments demand. Therefore, it is easier to process multiple variables and evaluate the interactions between factors [14-18, 22, 25]. Based on the traditional processing methods and limited knowledge of the honey-fried ephedra, we utilized the BBD to develop a mathematical model investigating the relationship between the three parameters (contents of honey, frying temperature, and frying time) in this study. The model, which was considered at multiaspects, has helped to provide reference for the clinical utilization of honey-fried ephedra.

3.6. LC-MS/MS Optimization. According to the carboxyl groups of the analytes, the amounts of $\mathrm{EH}, \mathrm{PEH}, \mathrm{MEH}$, and internal standard (IS) were analyzed in an ESI positive ion mode, and full-scan mass spectra of them after direct injection in the mobile phase were obtained. The results indicated that the ions of four analytes were all $[\mathrm{M}+\mathrm{H}]^{+}$ions, and the responses were very stable and showed good linearity in selected ion monitoring (SIM) mode. The quantitative analysis was carried out in SIM as follows: $\mathrm{EH}[\mathrm{M}+\mathrm{H}]^{+} \mathrm{m} / z$ 166.20, $\mathrm{PEH}[\mathrm{M}+\mathrm{H}]^{+} \mathrm{m} / z$ 166.20, $\mathrm{MEH}[\mathrm{M}+\mathrm{H}]^{+} \mathrm{m} / z$ 180.20, and IS $[\mathrm{M}+\mathrm{H}]^{+} \mathrm{m} / z$ 249.35. In order to increase sensitivity, ammonium acetate was tested as a modifier. Addition of $5 \mathrm{mM}$ ammonium acetate enhanced the sensitivity but with the poor peak shape. Thus, different proportions of formic acid $(0.05 \%-0.2 \%)$ were added to the mobile phase to improve peak shape. The results indicated that ammonium acetate $5 \mathrm{mM}$ and $0.1 \%$ formic acid $(\mathrm{v} / \mathrm{v})$ were adopted as the mobile phase for sufficient ionization response, good peak symmetry, and proper retention time for the analytes and IS.

3.7. Method Optimization. In order to develop a simple and efficient sample pretreatment to avoid matrix suppression and interference from endogenous plasma components for quantitation of the analytes in rat plasma, a variety of precipitants were investigated. Initially, several conventional liquid-liquid extraction (LLE) procedures were tested by using different extraction solvents such as acetocaustin and ether. Nevertheless, none of them was found suitable to give satisfactory and consistent recovery for all analytes. Therefore, plasma samples were subjected to protein precipitation procedure with acetonitrile and methanol. Furthermore, on account of enhancing the extraction recovery, different concentrations of sodium carbonate were investigated to observe whether they could achieve the purpose or not. Finally, $0.1 \mathrm{~mol} / \mathrm{L}$ sodium carbonate displayed favorable probably because the analytes were weak alkali; hence, certain alkali added could avoid the hydrolysis of them. Thus, acetonitrile along with $0.1 \mathrm{~mol} / \mathrm{L}$ sodium carbonate was employed to the pretreatment of the plasma samples.

In selecting the mobile phase procedure, we paid attention to the influence on the chromatographic peak shape and resolution. Acetonitrile was found superior to methanol to get better resolution with some smearing. Because the analytes were weak alkali, the smearing could be alleviated with the poor chromatographic peak shape after using $5 \mathrm{mM}$ 

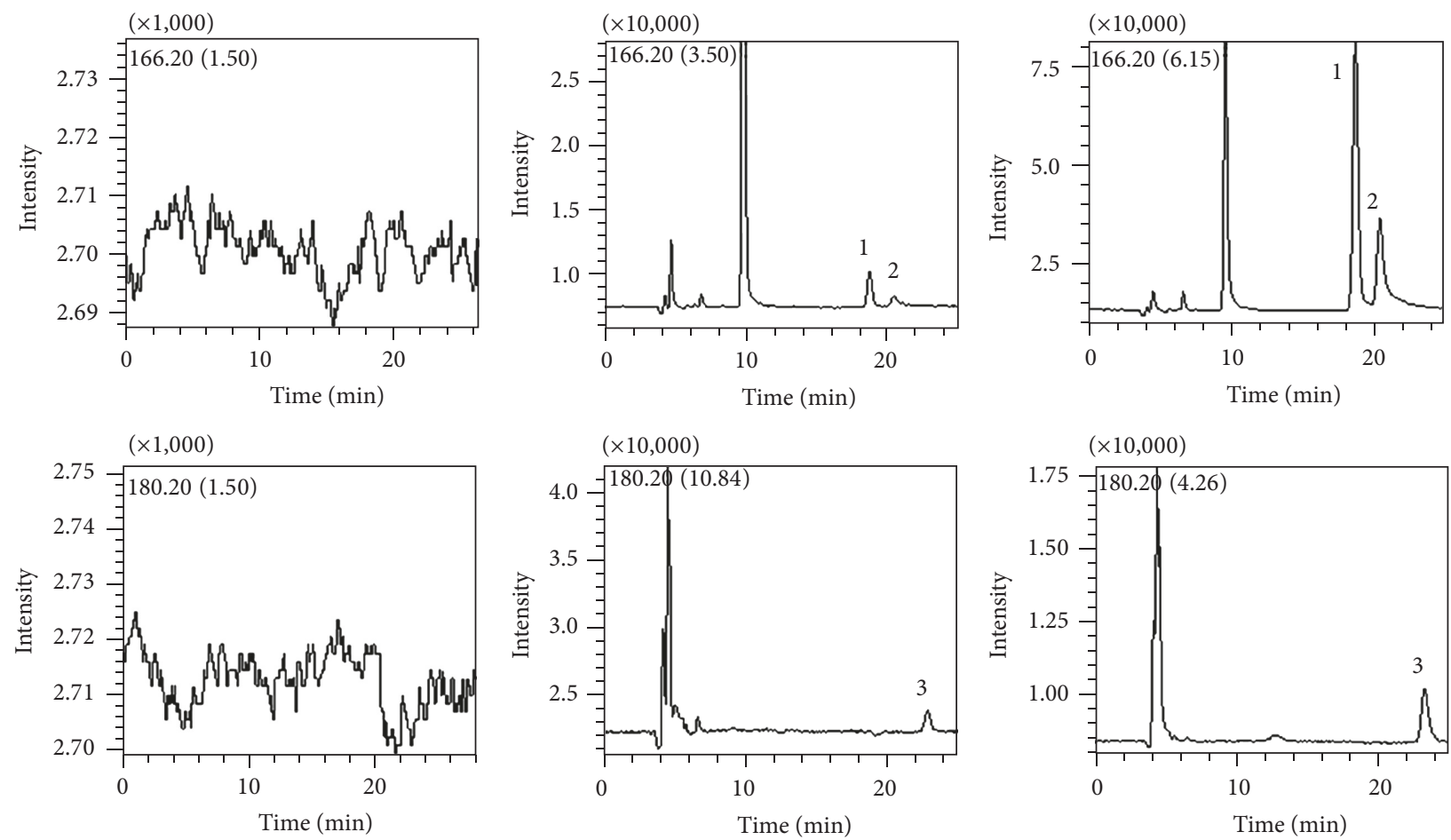

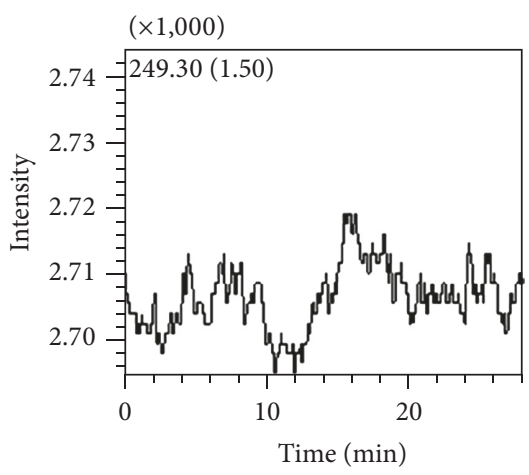

(a)

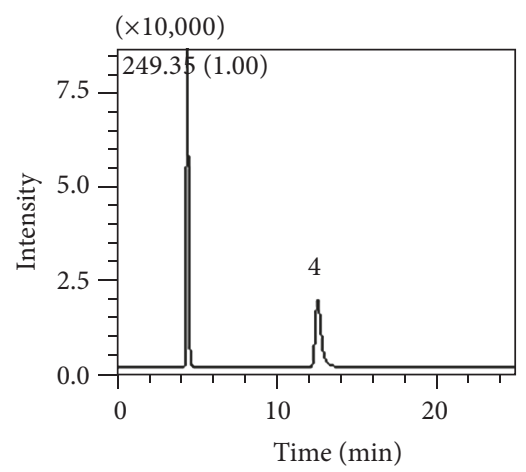

(b)

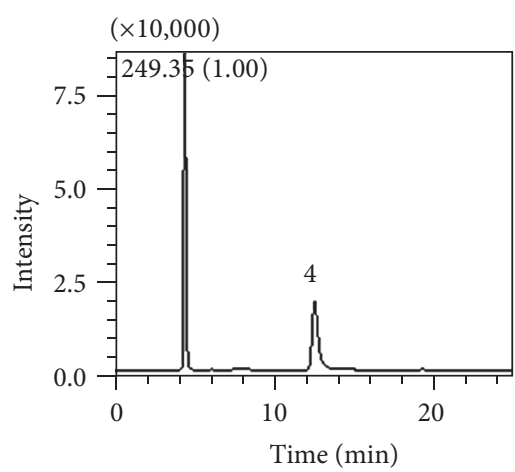

(c)

FIGURE 4: Representative chromatograms of blank rat plasma (a); blank rat plasma spiked with the three analytes at LLOQ and IS (b); rat plasma after $1.5 \mathrm{~h}$ after oral administration of the unprocessed ephedra extract (c). Peak 1: EH; 2: PEH; 3: MEH; 4: IS.

ammonium acetate buffer. The addition of $0.1 \%$ formic acid and $5 \mathrm{mM}$ ammonium acetate buffer was performed to obtain higher response, better chromatographic peak shape, and shorter run time.

3.8. Method Validation. Typical chromatograms obtained from blank plasma, blank plasma spiked with analytes (at LLOQ) and IS, and rat plasma samples after $1.5 \mathrm{~h}$ oral administration of the unprocessed ephedra extract are shown in Figure 4. No endogenous interference or ion suppression was observed at the retention times of analytes and IS.

The calibration curves exhibited good linearity with the coefficients of correlation $(r)$ better than 0.993 . The precision and accuracy at the LLOQ for all the analytes were less than $12 \%$ and within 11.5 , respectively. Intraday and interday precision and accuracy of all the analytes were excellent within acceptance criteria (15\%). Linear ranges, slope, intercept, LLOQ, and correlation coefficients obtained from typical calibration curves are shown in Table 2. Intraday and interday precision and accuracy for all the analytes are listed in Table 3.

The recoveries of $\mathrm{EH}, \mathrm{PEH}, \mathrm{MEH}$, and IS were $77.8-82.0 \%, 81.9-85.9 \%, 79.6-88.3 \%$, and $92.8 \%$ at different concentration levels, respectively, which proved that the process of extraction was consistent, precise, and reproducible (Table 3). Results of matrix effects (Table 3 ) indicated that no significant ion suppression or enhancement was observed for the analytes.

The RSD of the stability precisions were less than $15 \%$, and the accuracy ranged from $85 \%$ to $115 \%$. The results showed that the three analytes stored within the conditions of the stability tests as mentioned above have been proved to be stable. 

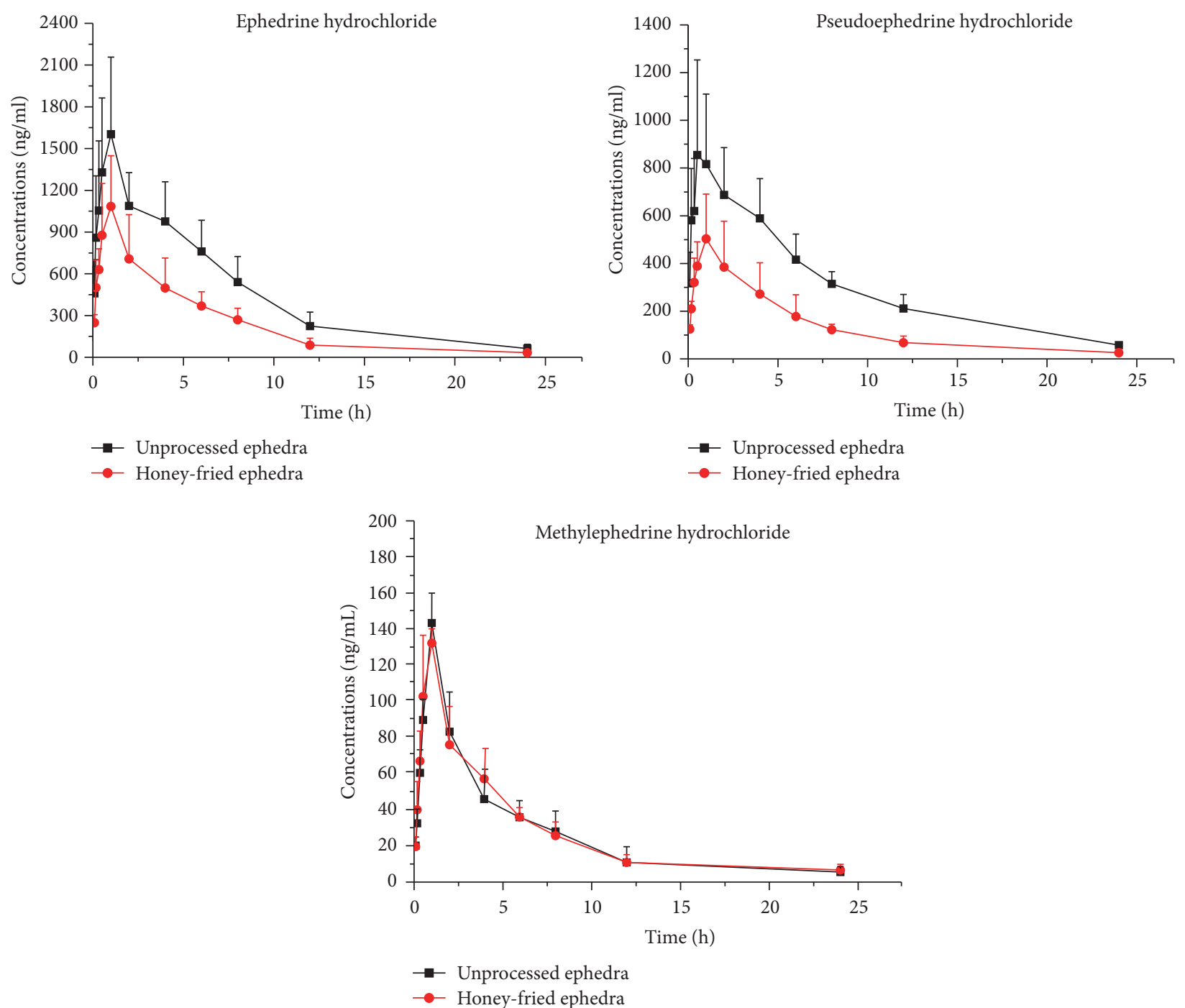

FIGURE 5: The mean concentration-time curves for $\mathrm{EH}, \mathrm{PEH}$, and $\mathrm{MEH}$ in rat plasma after oral administration of unprocessed ephedra extract and honey-fried ephedra extract. Each point represents mean $\pm \mathrm{SD}(n=6)$.

TABLE 2: Linear regression data of all the analytes in rat plasma.

\begin{tabular}{|c|c|c|c|c|c|c|c|}
\hline & \multirow{2}{*}{$\begin{array}{l}\text { Linear range } \\
(\mathrm{ng} / \mathrm{mL})\end{array}$} & \multirow{2}{*}{ Slope } & \multirow{2}{*}{ Intercept } & \multirow{2}{*}{$r$} & \multicolumn{3}{|c|}{ LLOQ (ng/mL) } \\
\hline & & & & & & $\mathrm{RE} \%$ & RSD\% \\
\hline$\overline{\mathrm{EH}}$ & $8-3200$ & $8.2 \times 10^{-3}$ & $1.7 \times 10^{-3}$ & 0.9952 & 8 & 6.3 & 7.2 \\
\hline PEH & $12-3000$ & $4.7 \times 10^{-4}$ & $5.0 \times 10^{-4}$ & 0.9932 & 12 & -3.5 & 5.8 \\
\hline $\mathrm{MEH}$ & $6-300$ & $4.4 \times 10^{-4}$ & $2.0 \times 10^{-3}$ & 0.9935 & 6 & 4.9 & 8.3 \\
\hline
\end{tabular}

3.9. Pharmacokinetics Studies. The developed method has been successfully applied to the comparative pharmacokinetics study of $\mathrm{EH}, \mathrm{PEH}$, and $\mathrm{MEH}$ in rat plasma after oral administration of unprocessed ephedra extract and honeyfried ephedra extract. The concentration-time curves (mean $\pm \mathrm{SD}$ ) of $\mathrm{EH}, \mathrm{PEH}$, and $\mathrm{MEH}$ are shown in Figure 5 and the corresponding pharmacokinetic parameters are listed in Table 4. As shown in Table 4 and Figure 5, the main differences in pharmacokinetics of $\mathrm{EH}, \mathrm{PEH}$, and $\mathrm{MEH}$ were $C_{\text {max }}$, $T_{\max }$, and AUC. Remarkable decreases $(P<0.05)$ in $C_{\max }$ and
$T_{\max }$ value of PEH $(954.8 \pm 307.8$ versus $510.5 \pm 189.6 \mu \mathrm{g} / \mathrm{L})$ and $(0.7 \pm 0.4$ versus $1.2 \pm 0.4 \mathrm{~h})$ were observed compared with the unprocessed ephedra extract. After oral administration of honey-fried ephedra extract, $\mathrm{AUC}_{0-t}$ and $\mathrm{AUC}_{0-\infty}$ of the $\mathrm{EH}$ and $\mathrm{PEH}$ decreased remarkably $(P<0.01)$, as compared with unprocessed ephedra extract. However, there were no significant differences in $\mathrm{AUC}_{0-t}, \mathrm{AUC}_{0-\infty}$, and $C_{\max }$ values of $\mathrm{MEH}$ between the unprocessed ephedra extract and honey-fried ephedra extract. The results indicated that oral administration of honey-fried ephedra extract could lead to 
TABLE 3: Precision, accuracy, recovery, and matrix effect for analyses of EH, $\mathrm{PEH}$, and $\mathrm{MEH}$ in rat plasma.

\begin{tabular}{|c|c|c|c|c|c|c|}
\hline & $\begin{array}{c}\text { Concentration } \\
(\mathrm{ng} / \mathrm{mL})\end{array}$ & $\begin{array}{l}\text { Intraday } \\
\text { RSD (\%) }\end{array}$ & $\begin{array}{l}\text { Interday } \\
\text { RSD (\%) }\end{array}$ & $\begin{array}{c}\text { Accuracy } \\
\text { RE (\%) }\end{array}$ & Recovery (\%) & Matrix effect (\%) \\
\hline \multirow{3}{*}{$\mathrm{EH}$} & 20 & 4.7 & 8.4 & 2.9 & $77.8 \pm 4.6$ & $89.3 \pm 2.9$ \\
\hline & 256 & 3.0 & 3.4 & -5.6 & $82.0 \pm 4.8$ & $96.6 \pm 1.7$ \\
\hline & 2560 & 6.7 & 10.9 & -4.6 & $79.3 \pm 1.4$ & $104.0 \pm 2.0$ \\
\hline \multirow{3}{*}{ PEH } & 30 & 6.1 & 11.5 & -4.1 & $83.4 \pm 5.0$ & $87.8 \pm 4.1$ \\
\hline & 240 & 5.2 & 9.3 & 2.0 & $85.9 \pm 3.7$ & $102.1 \pm 4.9$ \\
\hline & 2400 & 7.3 & 8.4 & -4.4 & $81.9 \pm 2.4$ & $90.7 \pm 3.1$ \\
\hline \multirow{3}{*}{$\mathrm{MEH}$} & 15 & 9.6 & 6.8 & 9.6 & $79.6 \pm 4.7$ & $97.6 \pm 4.8$ \\
\hline & 60 & 6.7 & 10.4 & -4.1 & $85.3 \pm 3.8$ & $88.4 \pm 5.1$ \\
\hline & 240 & 9.8 & 7.4 & 6.7 & $88.3 \pm 3.1$ & $94.0 \pm 5.3$ \\
\hline
\end{tabular}

poor absorption (AUC) for $\mathrm{EH}$ and $\mathrm{PEH}$, when compared with unprocessed ephedra extract. Besides, there was no significant difference in $T_{\max }$ and $t_{1 / 2}$ of $\mathrm{EH}$ and $\mathrm{MEH}$ from the ephedra and honey-fried ephedra group (Table 4).

To our knowledge, little research has been reported on the pharmacokinetics of unprocessed ephedra and honeyfried ephedra. In previous reports, other analytical methods, including HPLC and GC-MS, have been applied to evaluate the chemical constitutions before or after processing and the comparison of pharmacological action. Due to limitations of the analysis method or the research directions, the above methods could not fully illustrate the processing mechanism. Therefore, a specific, sensitive, and accurate LC-MS/MS assay for the quantification of $\mathrm{EH}, \mathrm{PEH}$, and $\mathrm{MEH}$ in rat plasma was developed and validated. The method has been successfully applied to the pharmacokinetic study of $\mathrm{EH}, \mathrm{PEH}$, and $\mathrm{MEH}$ in the rats after oral administration of unprocessed ephedra extract and honey-fried ephedra extract.

The absorption of EH, PEH exerted significant effect on diaphoresis and general effect on relieving cough and asthma; meanwhile, the absorption of $\mathrm{MEH}$ exerted primary effect on relieving cough and asthma. In addition, the pharmacokinetics results (Figure 5) showed that the possible reason for the reduced absorption of $\mathrm{EH}$ and $\mathrm{PEH}$ in honey-fried ephedra group might be the main reason for the decrease of the bioavailability, which confirmed the theory of that honeyfried ephedra extract could moderate the diaphoretic property of the unprocessed ephedra extract obviously. Meanwhile, there was no significant difference in the absorption of $\mathrm{MEH}$ between the unprocessed ephedra extract and honeyfried ephedra extract group. Hence, honey-fried ephedra extract not only eliminates the effect of diaphoresis but also weakens the effect of relieving cough and asthma. The theory that honey-fried ephedra extract could be used for treatment of the elderly, children, or weak patients with cough and asthma exclusively was confirmed.

\section{Conclusions}

RSM was confirmed to be a useful technique for the optimization to describe the honey-fried ephedra processing process and to identify experimental variables (different contents of honey, frying temperature, and frying time). After applying response surface experimental design, we optimized and determined the processing technology of the best effect honey-fried ephedra. Furthermore, the developed LC-MS/MS method was found to meet the requirements of pharmacokinetic studies of the $\mathrm{EH}, \mathrm{PEH}$, and $\mathrm{MEH}$ in rat plasma after oral administration of unprocessed ephedra extract and honey-fried ephedra extract. Results of this study demonstrated that pharmacokinetic behaviors of $\mathrm{EH}$, $\mathrm{PEH}$, and $\mathrm{PEH}$ were different after honey-fried ephedra and unprocessed ephedra were administered. These results may be helpful for the application of ephedra and honey-fried ephedra in clinical therapy.

\section{Conflicts of Interest}

The authors declare there are no conflicts of interest.

\section{Authors' Contributions}

All authors contributed to the manuscript preparation. Yezhe Cheng contributed to the conception of the experiments and performed the experiments; Yu Zhang analyzed the data and prepared the manuscript; Hang Xing helped to draft and revise the manuscript; Kun Qian played an important role in performing the analysis with constructive discussions. Longshan Zhao approved the final version. Xiaohui Chen provided the reagents, materials, and analysis tools and help to design experiments. All authors read and approved the final manuscript.

\section{Acknowledgments}

The authors would like to thank Associate Professor YanNian Wang of School of Traditional Chinese Materia Medica School of Shenyang Pharmaceutical University for his generous help in identifying the ephedra and preparation of voucher specimen. 


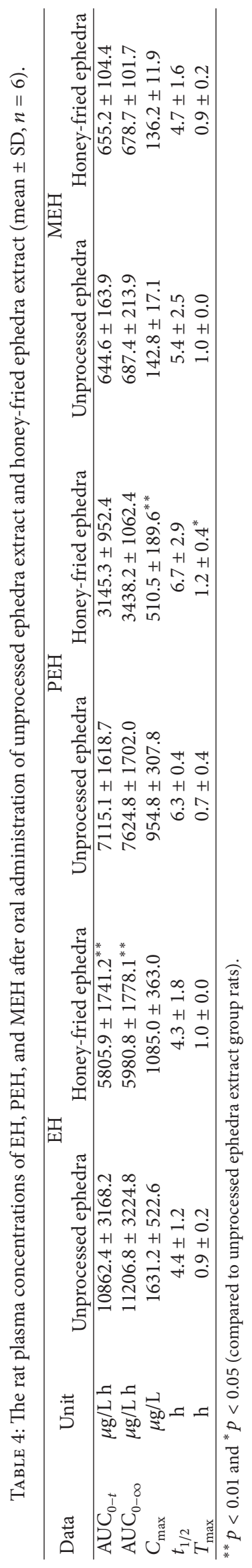




\section{References}

[1] M. R. Lee, “The history of Ephedra (ma-huang)," Journal of the Royal College of Physicians of Edinburgh, vol. 41, no. 1, pp. 78-84, 2011.

[2] L. Bielory, "Complementary and alternative interventions in asthma, allergy, and immunology," Annals of Allergy, Asthma and Immunology, vol. 93, no. 1, pp. 45-54.

[3] E. A. Abourashed, A. T. El-Alfy, I. A. Khan, and L. Walker, "Ephedra in perspective-a current review," Phytotherapy Research, vol. 17, no. 7, pp. 703-712, 2003.

[4] J. K. Dunnick, G. Kissling, D. K. Gerken, M. A. Vallant, and A. Nyska, "Cardiotoxicity of Ma Huang/caffeine or ephedrine/caffeine in a Rodent model system," Toxicologic Pathology, vol. 35, no. 5, pp. 657-664, 2007.

[5] K. J. Kemper, M. Singla, and P. Gardiner, "Herbs and dietary supplements for asthma," Clinical Pulmonary Medicine, vol. 12, no. 2, pp. 67-75, 2005.

[6] M. C. Roman, "Determination of ephedrine alkaloids in botanicals and dietary supplements by HPLC-UV: collaborative study," Journal of Aoac International,, vol. 87, pp. 1-14.

[7] N.-H. Nam, C.-W. Lee, D.-H. Hong, H.-M. Kim, K.-H. Bae, and B.-Z. Ahn, "Antiinvasive, antiangiogenic and antitumour activity of Ephedra sinica extract," Phytotherapy Research, vol. 17, no. 1, pp. 70-76, 2003.

[8] B. T. Schaneberg, S. Crockett, E. Bedir, and I. A. Khan, "The role of chemical fingerprinting: Application to Ephedra," Phytochemistry, vol. 62, no. 6, pp. 911-918, 2003.

[9] A. O. Shakil, D. Kramer, G. V. Mazariegos, J. J. Fung, and J. Rakela, "Acute liver failure: Clinical features, outcome analysis, and applicability of prognostic criteria," Liver Transplantation, vol. 6, no. 2, pp. 163-169, 2000.

[10] J. Zhu, P. Zhang, W. X. Zeng, and Q. F. Gong, "Research progress of ephedra processing," Journal of Jiangxi University of Traditional Chinese Medicine.

[11] Y. Xia, H. Kuang, B. Yang et al., "Optimum extraction of acidic polysaccharides from the stems of Ephedra sinica Stapf by BoxBehnken statistical design and its anti-complement activity," Carbohydrate Polymers, vol. 84, no. 1, pp. 282-291, 2011.

[12] K. Chen, X. U. Xiao-Feng, W. J. Lin, and L. Lin, "Analysis of chemical components on ephedra before and after honey-fried by GC-MS," Lishizhen Medicine and Materia Medica Research.

[13] L. Zhong, J. Zhu, Q. Gong, and D. Zhang, "The study on the influence of processing on the effects of diaphoresis and relieving ashtma of Ephedra herb," Pharmacology and Clinics of Chinese Materia Medica.

[14] X. Duan, Z. Zhang, C. Srinivasakannan, F. Wang, and J. Liang, "Regeneration of spent catalyst from vinyl acetate synthesis as porous carbon: Process optimization using RSM," Chemical Engineering Research and Design, vol. 92, no. 7, pp. 1249-1256, 2014.

[15] P. Elavarasan, K. Kondamudi, and S. Upadhyayula, "Statistical optimization of process variables in batch alkylation of p-cresol with tert-butyl alcohol using ionic liquid catalyst by response surface methodology," Chemical Engineering Journal, vol. 155, no. 1-2, pp. 355-360, 2009.

[16] C.-Y. Gan, N. H. Abdul Manaf, and A. A. Latiff, "Optimization of alcohol insoluble polysaccharides (AIPS) extraction from the Parkia speciosa pod using response surface methodology (RSM)," Carbohydrate Polymers, vol. 79, no. 4, pp. 825-831, 2010.
[17] E. Karacabey and G. Mazza, "Optimisation of antioxidant activity of grape cane extracts using response surface methodology," Food Chemistry, vol. 119, no. 1, pp. 343-348, 2010.

[18] L. M. Paucar-Menacho, M. A. Berhow, J. M. G. Mandarino, E. G. de Mejia, and Y. K. Chang, "Optimisation of germination time and temperature on the concentration of bioactive compounds in Brazilian soybean cultivar BRS 133 using response surface methodology," Food Chemistry, vol. 119, no. 2, pp. 636-642, 2010.

[19] Y. Sun, J. Liu, and J. F. Kennedy, "Application of response surface methodology for optimization of polysaccharides production parameters from the roots of Codonopsis pilosula by a central composite design," Carbohydrate Polymers, vol. 80, no. 3, pp. 949-953, 2010.

[20] T. K. Trinh and L. S. Kang, "Response surface methodological approach to optimize the coagulation-flocculation process in drinking water treatment," Chemical Engineering Research and Design, vol. 89, no. 7, pp. 1126-1135, 2011.

[21] K. Zhong and Q. Wang, "Optimization of ultrasonic extraction of polysaccharides from dried longan pulp using response surface methodology," Carbohydrate Polymers, vol. 80, no. 1, pp. 19-25, 2010.

[22] A. R. Lomasney, C. Guillo, A. M. Sidebottom, and M. G. Roper, "Optimization of capillary electrophoresis conditions for a glucagon competitive immunoassay using response surface methodology," Analytical and Bioanalytical Chemistry, vol. 394, no. 1, pp. 313-319, 2009.

[23] C. D. White, B. J. Willis, K. Narayanan, and S. P. Dutton, "Identifying and Estimating Significant Geologic Parameters With Experimental Design," SPE Journal, vol. 6, no. 3, pp. 311324, 2013.

[24] J. J. Borkowski, "Spherical prediction-variance properties of central composite and Box-Behnken designs," Technometrics, vol. 37, no. 4, pp. 399-410, 1995.

[25] E. A. Abigail M, M. S. Samuel, and R. Chidambaram, "Hexavalent chromium biosorption studies using Penicillium griseofulvum MSR1 a novel isolate from tannery effluent site: BoxBehnken optimization, equilibrium, kinetics and thermodynamic studies," Journal of the Taiwan Institute of Chemical Engineers, vol. 49, pp. 156-164, 2015.

[26] W. N. A. W. Mokhtar, W. A. W. A. Bakar, R. Ali, and A. A. A. Kadir, "Deep desulfurization of model diesel by extraction with N,N-dimethylformamide: Optimization by Box-Behnken design," Journal of the Taiwan Institute of Chemical Engineers, vol. 45, no. 4, pp. 1542-1548, 2014.

[27] A. A. Oladipo, M. Gazi, and S. Saber-Samandari, "Adsorption of anthraquinone dye onto eco-friendly semi-IPN biocomposite hydrogel: Equilibrium isotherms, kinetic studies and optimization," Journal of the Taiwan Institute of Chemical Engineers, vol. 45, no. 2, pp. 653-664, 2014.

[28] S. Wang, Y. Hu, W. Tan et al., "Compatibility art of traditional Chinese medicine: from the perspective of herb pairs," Journal of Ethnopharmacology, vol. 143, no. 2, pp. 412-423, 2012.

[29] W. Zhao, A.-J. Deng, G.-H. Du, J.-L. Zhang, Z.-H. Li, and H.L. Qin, "Chemical constituents of the stems of Ephedra sinica," Journal of Asian Natural Products Research, vol. 11, no. 2, pp. 168-171, 2009.

[30] L. L. Ding, S. S. Shi, J. Cui, S. C. Wang, and Z. T. Wang, "Advances in research of chemical constituents and pharmacological activites of Ephedra," China Journal of Chinese Materia Medica, vol. 31, no. 20, 1661 pages.

[31] N. Okamura, H. Miki, T. Harada et al., "Simultaneous determination of ephedrine, pseudoephedrine, norephedrine and 
methylephedrine in Kampo medicines by high-performance liquid chromatography," Journal of Pharmaceutical and Biomedical Analysis, vol. 20, no. 1-2, pp. 363-372.

[32] S. D. Cooper, B. L. Fletcher, M. A. R. Silinski et al., "Determination of L-ephedrine, pseudoephedrine, and caffeine in rat plasma by liquid chromatography-tandem mass spectrometry," Journal of Analytical Toxicology, vol. 35, no. 6, pp. 341-348, 2011.

[33] S. Song, Q. Tang, H. Huo, H. Li, X. Xing, and J. Luo, "Simultaneous quantification and pharmacokinetics of alkaloids in herba Ephedrae-Radix Aconiti Lateralis extracts," Journal of Analytical Toxicology, vol. 39, no. 1, Article ID bku113, pp. 5868, 2015.

[34] A. Parsaeimehr, E. Sargsyan, and K. Javidnia, "A comparative study of the antibacterial, antifungal and antioxidant activity and total content of phenolic compounds of cell cultures and wild plants of three endemic species of Ephedra," Molecules, vol. 15, no. 3, pp. 1668-1678, 2010.

[35] F. Xiao, Q. Li, K. Liang et al., "Comparative pharmacokinetics of three triterpene acids in rat plasma after oral administration of Poria extract and its formulated herbal preparation: GuiZhiFuLing capsule," Fitoterapia, vol. 83, no. 1, pp. 117-124, 2012.

[36] K. Qu, J. Dai, L. Zhao et al., "A sensitive liquid chromatographicmass spectrometric method for simultaneous quantification of six iridoid glycosides from Zhi-zi-chi Decoction in rat plasma and its application to a pharmacokinetic study," Journal of Pharmaceutical and Biomedical Analysis, vol. 78-79, pp. 83-91, 2013. 


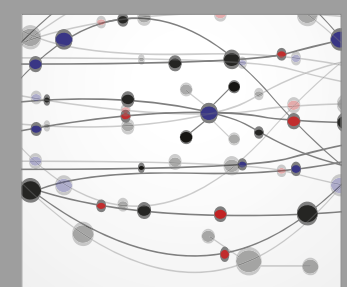

The Scientific World Journal
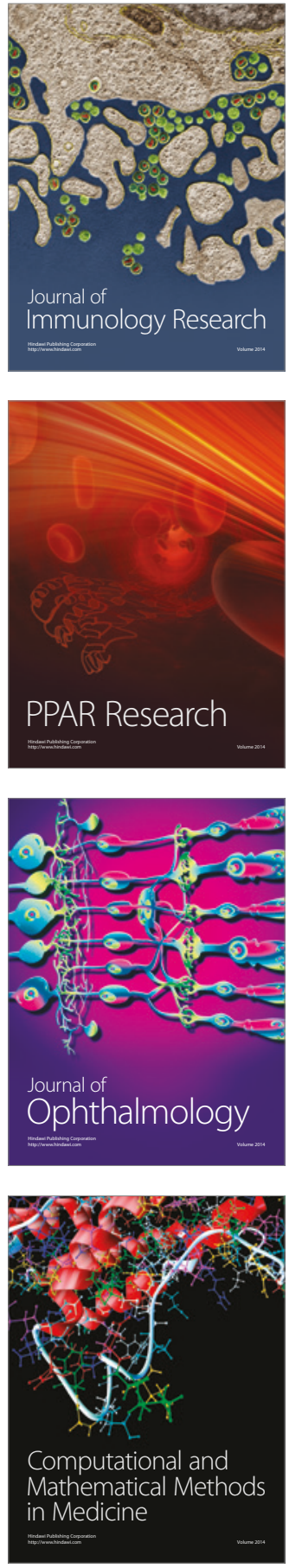

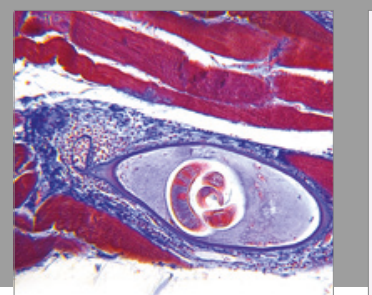

Gastroenterology Research and Practice
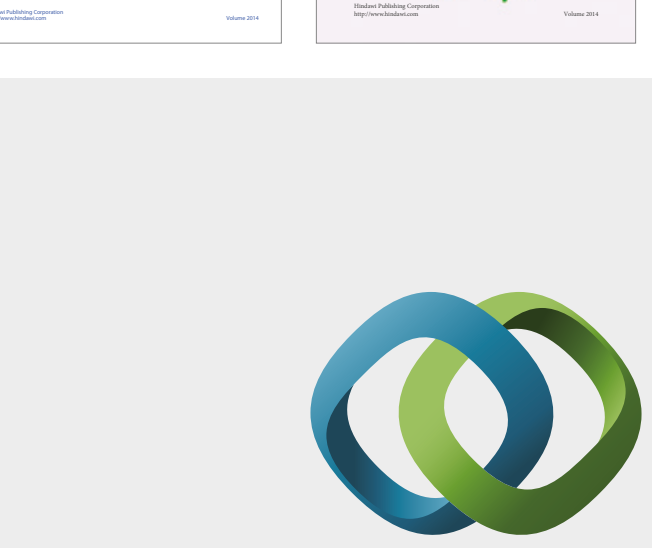

\section{Hindawi}

Submit your manuscripts at

https://www.hindawi.com
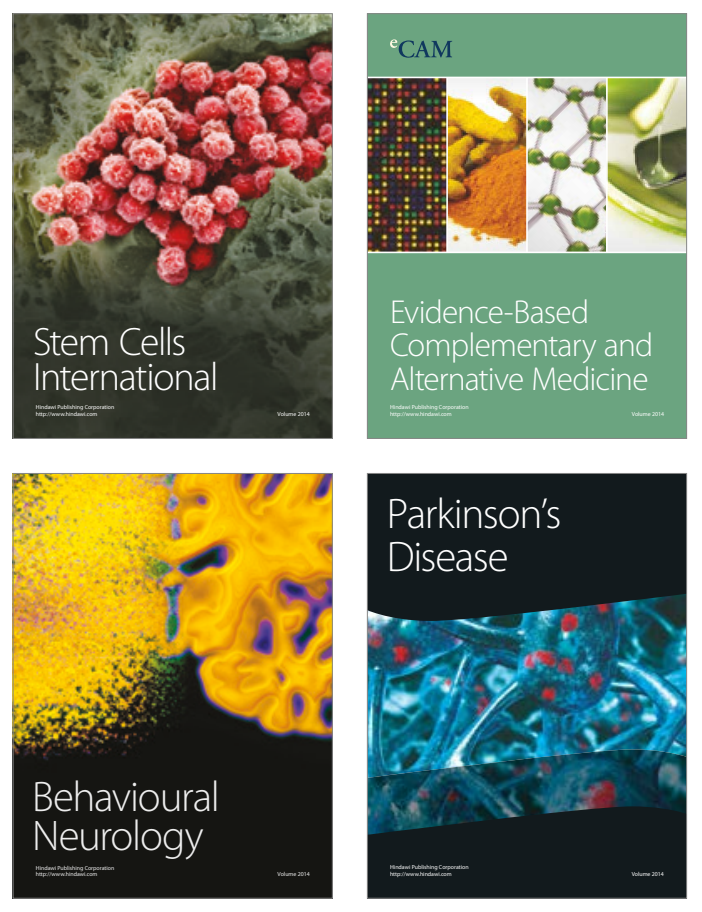
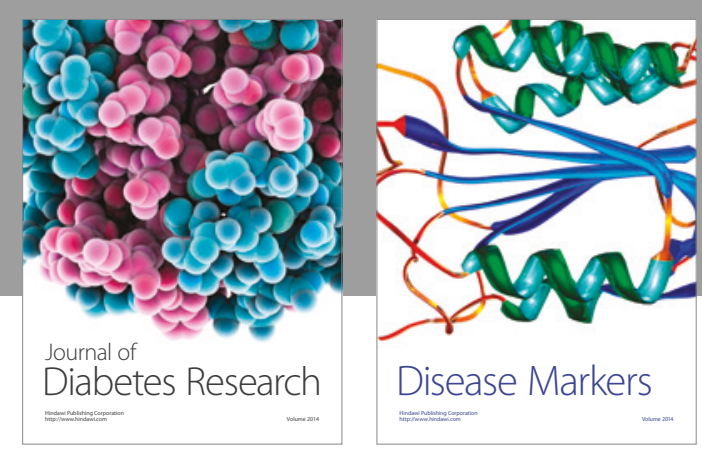

Disease Markers
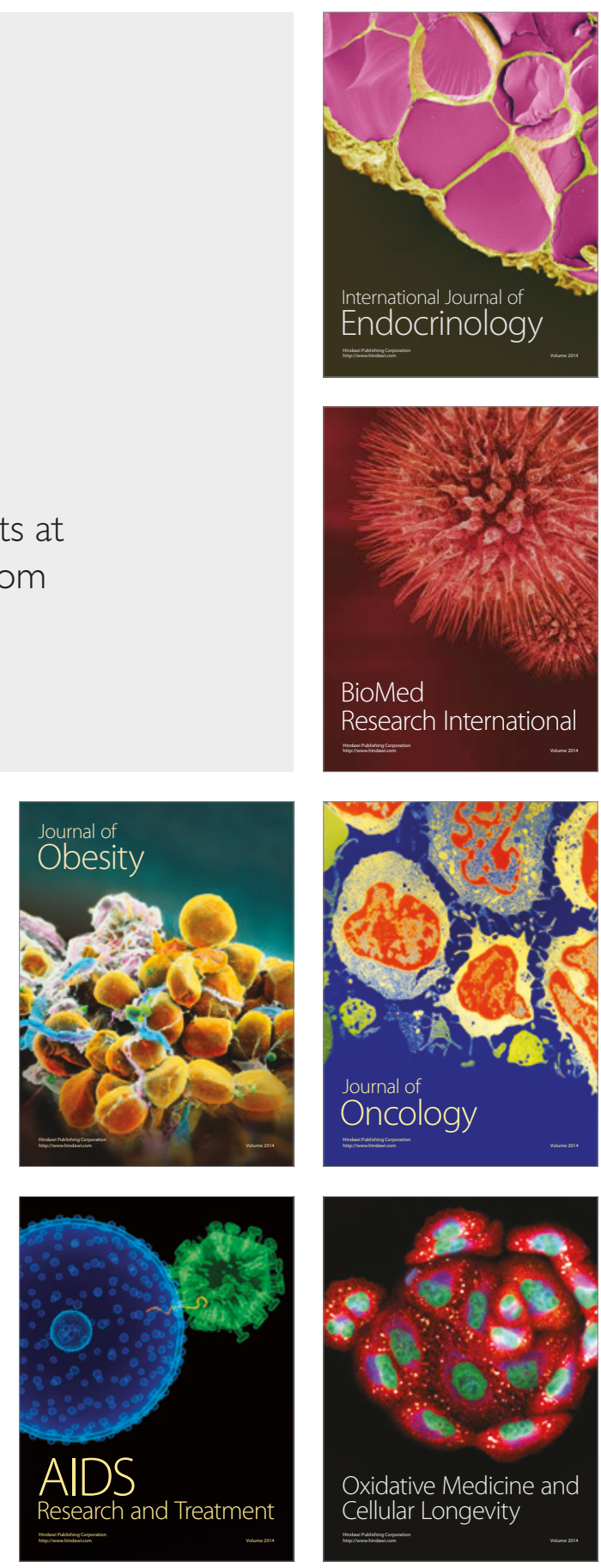